\title{
Pinilla, Julia y Brigitte Lépinette (eds.) (2015). \\ TRADUCCIÓN Y DIFUSIÓN DE LA CIENCIA Y LA TÉCNICA EN ESPAÑA (S. XVI-XIX) \\ Reseña: Natalia Campos Martín \\ Universitat de València
}

Autores: Julia Pinilla y Brigitte Lépinette (eds.) (2015).

Editorial: IULMA (Universitat de València)

Reseña: Natalia Campos Martín (Universitat de València)

Número de páginas: 286 páginas

ISBN: 978-84-370-9686-5

FECHA DE RECEPCIÓN: 4/09/2016

FECHA DE ACEPTACIÓN: 29/10/2016

PÁGINAS: 461-462

Sin duda el estudio de la Historia de la Traducción, máxime si está centrado en uno o varios ámbitos específicos del saber, como es el caso, nos permite conocer qué se hacía siglos atrás y comprobar hasta qué punto han cambiado tanto las cosas, al margen de la revolución tecnológica iniciada a finales del pasado siglo y que sí ha producido una revolución en la práctica profesional de la traducción, sobre todo en los ámbitos científico-técnicos.

En el caso que nos ocupa, presentamos una monografía colectiva, editada por dos académicas de reconocido prestigio dentro del ámbito de la Filología Francesa y de la Traducción e Interpretación, que se adentran en desgranar los pormenores de la traducción científica y técnica en Europa, prestando especial atención a la traducción del francés al español, aunque en algunos casos también se hacen alusiones a la literatura científica producida (y traducida) de otras lenguas.

En esta ocasión, se trata de una colección de 16 artículos especializados que se organizan en torno a tres grandes ejes temáticos:

\section{Parte I. Perspectiva general \\ Parte II. Tratados y manuales \\ Parte III. Lexicografía}

Estas tres partes hacen un acercamiento convergente al objeto de estudio, la traducción y la difusión de la ciencia y la técnica en España entre los siglos XVI y XIX.

Si en la primera parte, encontramos aportaciones como la Francisco Lafarga, en la que se investiga sobre la relación existente entre la historia de la traducción y la historia de la traducción científica y técnica, con sus luces y sus sombras, o con sus «encuentros y desencuentros», en la parte II encontramos ilustraciones sobre esos «encuentros y desencuentros».

Es indudable que los avances científicos y técnicos han tenido, desde la antigüedad clásica, una gran repercusión internacional, y han sido objeto preferente de traducción y de difusión más allá de las fronteras donde se produjeron. A este respecto, sorprende gratamente comprobar hasta qué punto disciplinas tan dispares como la Geometría, la Historia Natural, la obra de Darwin, la Medicina o incluso el ámbito militar son objeto de traducción con la mirada puesta en difundir nuevas percepciones de la realidad, entendida esta desde un punto de vista científico o técnico.

Por último la tercera parte incide en el estudio de la lexicografía como exponente de esa ingente labor traductora que se lleva a cabo en el período objeto de estudio (siglos XVI a XIX). Es indudable que la construcción de los lenguajes especializados en España es deudora, en muchos casos, de las traducciones que precedieron a la difusión de esos nuevos hallazgos o desarrollos (científicos o 
tecnológicos) que se producían fuera de nuestras fronteras. Prueba de ello son el gran número de préstamos que fueron incorporados en esos siglos a nuestra lengua, en forma, en muchos casos, de términos especializados de los ámbitos más variados, con especial atención, como se observa en esta monografía colectiva, a la producción científica y técnica.

El resultado es una monografía de magnífica factura, compuesta, como apuntábamos más arriba, por 16 capítulos, un apartado de bibliografía y un prólogo, que responden a los títulos que se recogen a continuación:

\section{Prólogo}

\section{Parte I. Perspectiva general}

1. Historia de la traducción e historia de la traducción científica y técnica: encuentros y desencuentros

2. Una aproximación bibliométrica a las obras traducidas del francés durante los siglos XVI-XIX

3. Science, politique et voyages en traduction en Amérique hispanique

\section{Parte II. Tratados y manuales}

4. La traducción de textos científico-técnicos en español en el Renacimiento: algunos rasgos caracterizadores

5. La traducciones al español e italiano del libro de Geometría (1532) de Oronce Finé: convergencia terminológica

6. Las traducciones de manuales de humanidades en la segunda parte del siglo XVIII. Las lógicas.

7. La variación denominativa en la versión española de la Histoire Naturelle de Buffon.

8. Fugaces novedades y largas persistencias: la terminología química y la profesión farmacéutica durante la primera mitad del siglo XIX.

9. Aspectos de la traducción científica en el siglo XIX: el ejemplo de Orfila.

10. Des «vilaines infidèles» à la postérité: traduction et retraduction de l'œuvre de Charles Darwin.

11. Los manuales de procedencia francesa en la enseñanza y difusión de la física eléctrica en España a lo largo del siglo XIX.

12. Nacimiento de la ciencia económica: análisis de las traducciones españolas del Epitome de JeanBaptiste Say.

13. Les traductions espgnoles de textes médicaux au debut du XIXe siècle (1800-1810)

\section{Parte III. Lexicografía}

14. La traducción según los prólogos de los diccionarios francés-español (siglos XVI-XIX)

15. La lexicographie militaire française et espagnole au XIXe siècle

16. Un ejemplo de la corriente traductora en la lexicografía especializada: el Diccionario militar (1749) de Raimundo Sanz

\section{Bibliografía}

Poco más nos resta por añadir. Invitamos a una lectura fructífera de la monografía y esperamos que esta lectura abra los ojos a una lectura más amplia de la difusión de la ciencia y de la técnica por mediación de procesos de traducción, algo que, para sorpresa de muchos, no es solo algo que caracterice a los siglos XX y XXI, sino que tiene unos antecedentes bien asentados en siglos precedentes, como los que son objeto de consideración en esta obra. 